\title{
Rousseau racionalista: três leituras
}

\author{
The rationalist Rousseau: three readings
}

Emanuele Tredanaro

emanuele.tredanaro@dch.ufla.br

(Universidade Federal de Lavras, Minas Gerais, Brasil)

\begin{abstract}
Resumo: “Rousseau est-il rationaliste?”. Essa pergunta abre a primeira das análises que Robert Derathé dedica ao genebrino. Derathé insere-se em um debate já amadurecido durante aproximadamente quatro décadas, e impulsionado explicitamente por Ernst Cassirer, cujas teses Eric Weil levará às últimas consequências. Cumpriremos aqui uma incursão nas interpretações que Cassirer, Derathé e Weil propõem acerca do racionalismo de Rousseau, apontando para a peculiaridade das conclusões às quais chega cada um deles, embora todos compartilhem a recusa de ler Rousseau como mero philosophe de la sensiblerie. Nessa perspectiva, o confronto com o kantismo tornar-se-á essencial para entendermos a fecundidade das três leituras.
\end{abstract}

Palavras-chave: Rousseau; Cassirer; Derathé; Weil; racionalismo.

\begin{abstract}
Rousseau est-il rationaliste?". This question opens the first of the analyses that Robert Derathé dedicates to the Genevan. Derathé fits into a debate already matured in nearly four decades, and explicitly stimulated by Ernst Cassirer, whose thesis will be brought to the last consequences by Eric Weil. Here we will do a foray in the interpretations that Cassirer, Derathé and Weil suggest about Rousseau's rationalism, pointing to the peculiarity of the conclusions to which each of them comes, although all of them share the refusal to read Rousseau as a mere philosophe de la sensiblerie. In this perspective, the comparison with the Kantianism will become essential to understand the fecundity of the three readings.
\end{abstract}

Keywords: Rousseau; Cassirer; Derathé; Weil; rationalism.

Em 1853, no terceiro tomo de seu Système de Politique positive, ao pronunciar sua crítica explícita à école politique de Rousseau - definida como declamatória, incapaz de construir qualquer coisa, portanto anárquica e fadada à instauração da desigualdade -, Comte acaba reconhecendo, no entanto, que, mesmo "possuindo apenas uma doutrina aparente", o Contrat social durante os anos da Revolução francesa "inspirará maior confiança e veneração do que aquela que a Bíblia e o Alcorão jamais obtiveram” (Comte, 1853, III.vii, pp.596-597). A observação de Comte tornase, para nós, interessante basicamente por um motivo: por ela ser paradigmática. Pois, sem que seja esta a intenção do autor (ou exatamente por não ser esta a sua intenção), a crítica de Comte retoma, ao salientá-la, a eficácia do pensamento político rousseauniano. E nem tanto pelo que Comte diz em sua constatação final 
acerca da fortuna política do Contrat durante a Revolução; mas, em primeiro lugar, performaticamente, pelo que a leitura de Comte representa por si mesma, isto é, mais uma das leituras possíveis de Rousseau. Aliás, é exatamente o tom peremptório usado por Comte a mostrar em que consiste a constante da fortuna de Rousseau: a deliberada ambiguidade ínsita no próprio texto de Rousseau, o qual assim se presta à multiplicidade mais variada de interpretações, até as mais radicais ou peremptórias ou hiperbólicas, como justamente a de Comte. De resto, não é preciso lembrar o que é notório, isto é, que desde o início foi possível puxar a proposta política de Rousseau para tudo quanto é lado. ${ }^{1}$

Se estiver corroborada a ideia de que a influência do pensamento político de Rousseau se deve, em última instância, a certa indeterminação e abertura que o próprio Rousseau alimenta, gostaríamos então de mostrar como tal ideia tenciona o texto rousseauniano não somente quanto às oscilações de seu conteúdo, mas ao mesmo tempo com relação ao modus philosophandi aí em ação. É nesse intuito que pretendemos resgatar a talvez mais relevante controvérsia exegética acerca do método de investigação de Rousseau, a relativa ao papel de sentimento e racionalidade na elaboração da filosofia rousseauniana, controvérsia, esta, que converge com aquela por sua vez relativa à possibilidade de identificar em Rousseau um pensador sistemático. Mais detidamente, visando mostrar alguns possíveis desdobramentos desse debate, e propor algumas observações a tal propósito, abordamos aqui as propostas interpretativas que Cassirer, Derathé e Weil apresentam na primeira metade do século XX.

Antes de tudo, é oportuno lembrarmos que a querela entre os intérpretes que veem em Rousseau um filósofo errante cujas especulações são guiadas pelo sentimento, e os que em Rousseau encontram um pensador racionalista e sistemático, representa o legado hermenêutico mais consistente que a veiculação do pensamento rousseauniano na Alemanha do século XVIII transmite ao século XX. Como justamente aponta Cassirer,

esta imagem tradicional [de Rousseau] formou-se historicamente através da "Época do Gênio" e do romantismo. Na Alemanha foi a geração do "Sturm und Drang" que viu em Rousseau seu progenitor e padroeiro. Essa geração o considerou como o profeta de um novo evangelho da natureza e como o pensador que redescobrira a potência

\footnotetext{
1 Durante a Revolução, por exemplo, Rousseau inspirou tanto Robespierre, Saint-Just, e, posteriormente, Babeuf, bem como foi aproveitado por conservadores como Du Theil, e até reacionários como Lenormant e Ferrand. Em época imperial, para Constant, o Contrat social, embora não fosse mais reimprimido, era a fonte do despotismo tanto revolucionário quanto napoleônico; por sua parte, Napoleão atribuía à obra-prima de Rousseau o surgimento do anarquismo revolucionário. E, após a Restauração, à mencionada leitura de Comte, por exemplo, se contrapunha a libertária de Victor Hugo ou a de Engels, que encontrava na análise rousseauniana o sinal da benéfica difusão da peste dialética. $O$ esquema se repete no século XX, ao longo do qual Rousseau é lido, por exemplo, seja em chave radicalmente liberal por Popper, seja em chave liberal-democrática por Rawls, seja em chave comunitarista por Nisbet.
} 
originária de emoções e paixões, e as libertara de qualquer constrição, da constrição das convenções assim como daquela da "razão". Também a crítica moderna não infrequentemente aceitou essa interpretação e embasou nela todas as acusações contra o visionário, sonhador e entusiasta Rousseau (Cassirer, 1945, p.13).

Quando Cassirer se refere à “crítica moderna”, ele está apontando não apenas para a exegese rousseauniana da última parte da modernidade, mas também para a que se desenvolve daí até a época a ele contemporânea. Cassirer formula essa sua avaliação no ensaio de 1939, Kant und Rousseau. ${ }^{2}$ Na verdade, trata-se da retomada de motivos historiográficos e sugestões interpretativas propostos desde Kants Leben und Lehre de 1918 e, novamente, no mais amplo ensaio sobre Rousseau de 1932, Das Problem Jean-Jacques Rousseau, que, por sua vez, reelabora os temas da conferência parisiense de 27 de fevereiro do mesmo ano, L'unité dans l'œuvre de J.-J. Rousseau. Cassirer mostra como o mencionado direcionamento em sentido romântico da exegese rousseauniana alemã, ao fim do século XVIII, se insere na mais geral virada filosófica que se contrapõe à Aufklärung, retomando exigências interpretativas até então colocadas em segundo plano pela inicial recepção alemã de Rousseau.

Na década de 60 do século XVIII, naquele período crucial pela influência de Rousseau sobre Kant, sua doutrina [de Rousseau] foi enxergada sob outra luz. Para esse período Rousseau não foi em primeira instância o restaurador dos direitos das emoções, o apóstolo da "sentimentalidade"; ele foi, como Kant o denomina, o "restaurador dos direitos da humanidade". Não apenas Kant, mas Lessing também exprimiu o mesmo juízo (Cassirer, 1945, p.13).

Graças a Lessing e Kant, e em geral à sensibilidade cultural estimulada pela Aufklärung, são o valor moral do homem e o respeito pela virtude que desde logo assumem centralidade, segundo Cassirer, na primeira e mais imediata recepção de Rousseau na Alemanha contemporânea aos escritos do filósofo genebrino. Torna-se paradigmática nesse sentido até uma obra que posteriormente será tomada como modelo de glorificação do sentimento e da paixão, La Nouvelle Héloïse. ${ }^{3}$ A energia que inflama o amor de Julie para Saint Preux, afinal, torna-se meio para assinalar o conflito constante entre paixão e virtude, o qual revela a verdadeira natureza do

\footnotetext{
20 ensaio, escrito em 1939 durante seu exílio em Göteborg, representa a primeira obra póstuma de Cassirer, sendo publicado, traduzido para o inglês, em Princeton, no próprio ano da morte do autor, em 1945, junto com outro ensaio Goethe and the Kantian Philosophy, escrito em 1944. A publicação estava planejada há tempo, como confirma o prefácio que Cassirer escrevera para a edição americana, em outubro de 1944, já em solo estadunidense. Ao justificar a coletânea, Cassirer acaba explicando o intuito sistemático dos dois ensaios no interior de sua produção filosófica: "Os dois ensaios deste pequeno livro abordam assuntos diferentes, mas têm um tema em comum. Eles tentam esclarecer, a partir de diversas perspectivas, a cultura do século XVIII e o "clima de opinião" - por usar o termo de Whitehead - do qual surgiu essa cultura. Abordei esse tema mais detalhadamente em meu livro Die Philosophie der Aufklärung. Enquanto estou preparando uma nova edição revista desta obra para o inglês, que aparecerá em breve, espero que estes ensaios possam ser lidos como uma espécie de introdução ao mais amplo volume" (Cassirer, 1945, p.XVII).
}

3 Acerca da recepção de La Nouvelle Héloïse, cf. Taylor, 1963, Attridge, 1974 e Labrosse, 1985. 
homem como ser híbrido.

Sabia-me bem nascida e entregava-me a minhas inclinações, gostava de refletir e fiava-me em minha razão; não podendo conciliar o espírito do evangelho com o do mundo, nem a fé com as obras, escolhera um meio termo que contentava minha vã sabedoria; possuía máximas para crer e outra para agir; esquecia num lugar o que pensara em outro, era devota na Igreja e filósofa em casa (...). Um feliz instinto levame ao bem, uma violenta paixão se levanta, tem suas raízes nesse mesmo instinto: que farei para destruí-la? Da consideração da ordem extraio a beleza da virtude e sua bondade da utilidade comum; mas que significa tudo isso diante meu interesse particular e o que, no fundo, me importa mais, minha felicidade a expensas do resto dos homens ou a felicidade dos outros a expensas da minha? (...) Enfim, se o caráter e o amor do belo estiverem gravados pela natureza no fundo de minha alma, terei uma regra até eles não forem desfigurados. Mas como assegurar-me de que conservarei sempre em sua pureza essa efígie interior que não possui, entre os seres sensíveis, um modelo ao qual possa ser comparada? Não sabemos que as afeições desordenadas corrompem o juízo assim como a vontade, e que a consciência se altera e se modifica insensivelmente em cada século, em cada povo, em cada indivíduo, segundo a inconstância e a variedade dos preconceitos? (NH [parte III, carta 18], OC II, p.357358; p.315). ${ }^{4}$

É através da ênfase na capacidade de o homem se reconhecer, aceitar e orientar a partir de sua consciência da tensão natural que o anima, que - segundo Cassirer sobretudo Kant encontra em Rousseau o pensador que, melhor que os outros, soube atribuir à dignidade moral do homem sua merecida centralidade e primazia: os belos sentimentos do coração podem vacilar, enquanto a vontade sublime se assenta na firmeza da razão.

Através dessa impostação de sua reconstrução histórico-filosófica, Cassirer não apenas resgata a leitura racionalista de Rousseau, por assim dizer, a mais "original" e fiel, mas, sobretudo, acaba mostrando que aquele primeiro debate torna-se de fundamental importância para entendermos o debate do início do século XX, em que o principal eixo da querela iluminista-romântica acerca da exegese rousseauniana se renova, ao se relacionar à questão da sistematicidade do pensamento de Rousseau. Ainda em 1939, na resenha da literatura crítica filosófica dos anos 1937 e 1938, Die Philosophie im XVII. und XVIII. Jahrhundert, publicada em ocasião do terceiro centenário do Discours de la Méthode, Cassirer explicitamente retoma também a relação entre a controvérsia apenas mencionada e a da unidade sistemática da filosofia de Rousseau. Ao citar os mais recentes e louváveis trabalhos da época, Cassirer admite que,

\footnotetext{
4 Cf. também as palavras de Julie após a resposta de Saint-Preux: "Pois o coração nos engana de mil maneiras e só age por um princípio sempre suspeito, mas a razão não tem outra finalidade a não ser o bem, suas regras são seguras, seguras, fáceis na conduta de vida, e nunca se perde a não ser nas inúteis especulações que não são feitas para ela (NH [parte III, carta 20], OC II, p.370; p.326). As citações de Rousseau baseiam-se nas obras completas publicadas pela editora Gallimard, valendo as abreviaturas aqui explicitadas nas referências bibliográficas.
} 
embora todo o trabalho até aqui cumprido, a verdadeira questão fundamental ainda parece não ser: Em que consiste a doutrina filosófica de Rousseau; mas, sim: Se em geral se dá tal doutrina. Se aceitarmos a imagem que muitos intérpretes delinearam da personalidade de Rousseau e de seu desenvolvimento espiritual, temos que responder negativamente a essa pergunta. Conforme essa imagem, na obra de Rousseau não está presente algum traço unitário do pensamento; a obra de Rousseau apresentase apenas como a expressão de disposições pessoais, que mudam e assumem todas as mais variadas nuanças, dependendo do objeto considerado e das particulares circunstâncias de vida (Cassirer, 1939, p.77).

Nesse sentido, nos parece que a posição de Derathé, embora não se distancie da de Cassirer no que diz respeito à análise inicial, difira em seu desdobramento. Em seu célebre livro de 1948, Le rationalisme de Jean-Jacques Rousseau, Derathé recorda que,

a não ser que concluamos que seus escritos [de Rousseau] são cheios de incoerência, é preciso admitir (...) que suas contradições são puramente verbais, e procurar, além da discordância aparente das fórmulas, o verdadeiro pensamento do autor. É o que fazem seus intérpretes melhores. O leitor não espantará ao vê-los se dividirem em dois grupos: uns se esforçando em mostrar que, a despeito das inúmeras fórmulas racionalistas, a doutrina, assim como o método de Rousseau, é de inspiração sentimental; os outros afirmando que o apelo ao sentimento não impede Rousseau de permanecer essencialmente racionalista (Derathé, 1948, p.4).

Como Cassirer, Derathé também opta por uma interpretação sistemática do pensamento rousseauniano, assim como relaciona o caráter unitário da doutrina a um método de investigação que não seja rapsódico ou volúvel, conforme a representação romântica. O próprio Rousseau oferece uma interpretação de seu pensamento como desde o início definido de uma vez por todas quanto a seus eixos:

Escrevi sobre diversos assuntos, mas sempre segundo os mesmos princípios: sempre a mesma moral, a mesma crença, as mesmas máximas, e, se quiser, as mesmas opiniões. Juízos contraditórios, no entanto, foram feitos sobre meus livros, ou, antes, sobre o autor de meus livros, porque fui julgado pelos assuntos de que tratei muito mais do que por meus sentimentos (LCB, OC IV, p.928; p.40).

Ao contrário de Cassirer, porém, Derathé compatibiliza tal unidade sistemática doutrinal e metodológica seja com a interpretação sentimentalista de Rousseau seja com a racionalista. Mais especificamente, Derathé detém-se, para o grupo dos sentimentalistas, à análise de Pierre-Maurice Masson, La religion de Jean-Jacques Rousseau, de 1916, e, para o grupo dos racionalistas, à análise de Georges Beaulavon, La philosophie de J. -J. Rousseau e l'esprit cartésien, de 1937, assim como à de André Ravier, L'Education de l'homme nouveau, de 1941. ${ }^{5}$ Parece-nos que é justamente à

5 Derathé atribui à primeira tendência interpretativa os trabalhos de Léon Brunschvicg, Progrès de la conscience dans la philosophie occidentale (1927), Pierre Lasserre, Romantisme français (1908), e Jacques Maritain, Trois réformateurs (1925), assim como a posição de Victor Basch; enquanto refere à segunda, entre os outros, os trabalhos de Harald Höffding, Jean-Jacques Rousseau et sa 
assunção de compatibilidade entre a unidade sistemática do pensamento de Rousseau e o sentimento como motor de investigação filosófica, que deve ser atribuída a peculiaridade da sugestão hermenêutica de Derathé. Como Cassirer, Derathé também recusa sem meios termos a tentativa de apresentar Rousseau como o campeão do mero sentimento. Todavia, a partir da possibilidade de inserir também o sentimento dentro de um sistema unitário, Derathé aceita - e, como veremos sob certas condições mantém - a ideia de que sentimentalismo e racionalismo possam coexistir sem provocarem contradição. É nesse sentido que Derathé, mesmo simpatizando com a análise de Beaulavon, que resulta "decisiva" na controvérsia, não pode não constatar a necessidade de "completar e, sobre certos pontos, retificar" a dita interpretação. Se, de um lado, a Beaulavon há de se reconhecer o mérito de "ter mostrado que em Rousseau não há uma oposição, mas "uma constante colaboração entre sentimento e razão"” (Derathé, 1948, p.7), de outro lado, segundo Derathé, não é possível ignorar a cartesianização que Beaulavon faz de Rousseau, ao entender tal colaboração entre sentimento e razão univocamente no sentido do esclarecimento do sentimento por parte da razão. Nem parece satisfatória para Derathé a posição de Ravier, o qual, embora se afaste da tese de Masson - do mesmo modo que Beaulavon e Derathé -, e embora se distancie parcialmente da tese de Beaulavon - do mesmo modo que Derathé -, se limita a reconhecer o equilíbrio existente entre sentimento e razão, sem tomar partido, afinal, sem explicar como tal equilíbrio se realiza, coisa que lheimpede de ler Rousseau como propriamente racionalista, conforme a pretensão de Derathé.

A interpretação da relação entre sentimento e razão no que diz respeito à doutrina e ao método rousseaunianos, então, não pode privilegiar, segundo Derathé, uma visão meramente sentimentalista, nem a simples constatação da coexistência de sentimento e razão que ou leve de fato à redução do primeiro à segunda, ou negligencie fundamentar a justaposição.

O pensamento profundo de Rousseau - nota Derathé - seria, na verdade, que não há sã razão em um coração corrompido, e que a consciência mesma deve servir de princípio ou de regra para a razão, a qual, sem esse guia, risca de "extraviar-se de erro em erro" e de engendrar os piores sofismas. Nesse sentido a pureza do coração seria a condição da reta razão (Derathé, 1948, p.7).

Cassirer, de sua parte, já antecipava as perplexidades e, de certa forma, as conclusões de Derathé, de modo particular ao se debruçar justamente sobre a análise de Beaulavon. Na resenha de 1939, Cassirer dedica a Beaulavon o seguinte comentário tanto explícito quanto autocelebrativo:

philosophie (1912), Émile Durkheim, "Le Contrat social» de Rousseau (1918) e La "Pédagogie» de Rousseau (1919), D. Parodi, La philosophie religieuse de Rousseau (1912), e Albert Schinz, La Pensée religieuse de Rousseau et ses récents interprètes (1917) (cf. Derathé, 1948, pp.5-6). 
Nós concordamos com tais conclusões em todos os pontos essenciais e encontramos nelas confirmação de nossa própria interpretação do caráter fundamental da filosofia da religião de Rousseau (cf. Arch. Für Gesch. d. Philos., vol. 41, p.504ss. [Cassirer, 1932, pp.78ss.]). Mas não acreditamos que seja correto aproximar tanto Rousseau e Descartes, como ocorre no ensaio de Beaulavon (...) Pois, a razão de Descartes é e permanece sobretudo a razão teorética, cujo grande modelo é a matemática (...), mas a razão à qual [Rousseau] apela e cujos direitos sustenta é a "razão prática". Seu caminho [de Rousseau] aponta muito mais para Kant do que reenvia para Descartes (Cassirer, 1939, pp.78-79).

A crítica cassireriana a Beaulavon, todavia, se bem que conduzida na mesma direção da de Derathé, está voltada a uma conclusão apenas próxima à deste último, nos mesmos moldes que já ressaltamos, apontando para as distinções sutis existentes na maneira de os dois intérpretes fundamentarem sua opção hermenêutica em prol de uma leitura racionalista de Rousseau. Para Cassirer, ao contrário de que para Derathé, não parece haver alguma ressalva, devendo-se entender o racionalismo de Rousseau como imediatamente antissentimentalista. Não há, em outros termos, alguma cláusula de salvaguarda ou de resgate para elementos que reenviem à esfera sentimental. Consequentemente, a recusa de parte de ambos os intérpretes da aproximação do racionalismo de Rousseau ao de Descartes, também acarreta, nas conclusões, a distinção proposta no nível das premissas. Para Cassirer,

o "instinto divino", como ele [Rousseau] descreve o consciência moral, é para este de uma espécie e origem diferente de todas as verdades que o pensamento puro pode nos fornecer. Nem o sentimento e a paixão, nem o pensamento abstrato são capazes de enxergar a sua [do saber moral] natureza e origem. Na explicação do "fenômeno originário" religioso-moral, da "voz imortal e divina" da consciência, fracassa segundo Rousseau tanto o "sentimentalismo" como o "intelectualismo". 0 primeiro não consegue explicar a liberdade, a "espontaneidade" do eu; o segundo desentende essa espontaneidade, procurando sua raiz no pensamento puro, ao invés de que na vontade (Cassirer, 1939, p.79).

Ambos os intérpretes, o alemão e o francês, acabam retomando o apelo à consciência, como noção crucial para a explicação do racionalismo de Rousseau. E ambos reconhecem que a consciência refere-se diretamente ao âmbito prático, Cassirer com todas as letras, Derathé de maneira menos explícita, mas igualmente clara, pois os erros e sofismas mencionados são os que nos levam não ao desentendimento de verdades teóricas, mas à falha moral em nossas ações. Mas tal correspondência das interpretações revela-se apenas verbal, como confirmado pelos dois intérpretes. Para Cassirer são eminentemente a filosofia do direito e a filosofia política de Rousseau a mostrarem o desentendimento profundo da proposta rousseauniana, quando lida em chave sentimentalista, pois

ele [Rousseau], que foi o verdadeiro campeão do sentimento e dos "direitos do coração", em sua teoria do direito e do Estado refuta resolutamente a primazia do sentimento. Para as instituições jurídicas e políticas ele tem que procurar uma 
fundamentação diferente, pois, em sua concepção, elas são formas da vontade submetidas a uma lei peculiar, a uma legalidade sui generis. Está na natureza do Estado dever visar não à fusão dos sentimentos em uma unidade, mas ao contrário à unificação dos atos de vontade, direcionando-os a um objetivo comum (Cassirer, 1945, p.30).

A filosofia jurídico-política de Rousseau exemplifica paradigmaticamente seu método racionalista, já que, se, como dito anteriormente, não se tratar nem de sentimentos e paixões, nem da razão teorética, mas sim da consciência como voz da livre vontade do homem, de um lado, Rousseau estaria se deparando - em termos kantianos - com o caráter formal da vontade, isto é, com a vontade em geral (überhaupt), despojada de qualquer conteúdo material empiricamente determinado que caracteriza sentimentos e paixões; de outro, tratar-se-ia não mais da espontaneidade do intelecto que quer conhecer os objetos através de suas regras lógicas, mas da espontaneidade da razão que, enquanto puramente prática, agora visa unicamente mover a si mesma por si mesma, isto é, determinar suas deliberações e ações pela sua própria mera forma. "Esse entusiasmo pela lei como "voz universal" perpassa todos os escritos políticos e esboços de Rousseau" (Cassirer, 1945, p.45), acrescenta Cassirer. Apenas lembremo-nos das palavras de Rousseau no Discours sur l'économie politique:

Como é possível que todos obedeçam, embora ninguém assuma a posição de ordenar? Que todos sirvam, sem que haja senhores, e sendo mais livres ainda quando, em aparente sujeição, cada um só perde da sua liberdade a parte que pode ser prejudicial a outrem? Devemos essas maravilhas à Lei. É somente à Lei que os homens devem a Justiça e a Liberdade. Ela é esse órgão salutar da vontade geral que institui, no direito civil, a igualdade natural dos homens. É essa Voz celestial que dita a cada cidadão os preceitos da razão pública, ensinando-o a agir de acordo com as regras do seu próprio julgamento, e a não se conduzir de forma inconsistente consigo mesmo. (EP, OC III, p.248; p.11). ${ }^{6}$

Nós poderíamos acrescentar que tal entusiasmo pela lei da liberdade como voz universal perpassa também a leitura de Rousseau em chave kantianamente racionalista e sistemática por parte de Cassirer, o qual, exatamente nesse sentido, interpreta também a filosofia da religião, ponto nevrálgico da querela. ${ }^{7}$ À primeira vista, não tem como negar o papel do sentimento ao recordarmos a posição de Rousseau a favor da fundamentação da religião na escuta da voz de Deus em nosso coração, contra qualquer doutrina e tradição positiva. Nesse sentido cabe uma

6 Rousseau repetirá essas palavras, quase ao pé da letra, na primeira versão do Contrat social, o assim chamado Manuscrit de Genève (cf. MG [I.vii], OC III, p.310; p.143).

7 Lembremos que a interpretação sentimentalista de Masson estava embasada e focada nos escritos de filosofia da religião de Rousseau. O próprio Cassirer, mesmo reconhecendo Masson ter escrito "a mais exaustiva exposição que a teoria da religião recebeu", não deixa de salientar que, "porém, a crítica moderna provou com argumentos irrefutáveis que ela não consegue provar sua tese central" (Cassirer, 1945, pp.43-44). 
possível objeção: “Realmente - nota Cassirer - pode o coração nos mostrar o caminho para aquela única religião original, natural, que Rousseau procura e quer ensinar? (...) Essa objeção seria irrefutável, se Rousseau, como filósofo da religião, não fosse nada mais que o profeta da sentimentalidade" (Cassirer, 1945, p.46). Efetivamente parece que nos encontramos em um beco sem saída: se aceitarmos uma fundamentação rigorosamente sentimentalista da religião, não conseguimos explicar como o próprio Rousseau pode identificar no coração a origem unívoca e necessária - ou seja, universal - da religião, contra a multiplicidade e particularidade das doutrinas positivas; se, ao contrário, aceitarmos a ênfase que o próprio Rousseau põe na religião originária e natural, portanto necessária e universal, como a única que possa legitimamente guiar nossas ações, não conseguimos salvaguardar uma fundamentação sentimentalista da religião, isto é, sujeita à volubilidade das paixões. Para Cassirer, podemos abrir mão tranquilamente da primeira estratégia argumentativa, pois sua premissa conduziria realmente à contradição: como visto, assumir, nos moldes românticos, a volubilidade do sentimento - e agora, de maneira mais específica, do coração - como fonte da filosofia de Rousseau, acaba conflitando com qualquer tentativa de síntese, e leva, em última análise, à incoerência interna da própria filosofia rousseauniana. A segunda estratégia apresenta uma contradição que, enquanto aparente, pode ser superada, pois, em nome e em vista da coerência interna do sistema rousseauniano, deixa aberta a possibilidade e indica a necessidade de redefinição do significado de sentimento, a saber, como apelo à consciência da razão pura prática.

A sua [de Rousseau] religião do "sentiment" não pretende ser de modo algum uma religião da "sentimentalidade". Pois, aqui também aplica-se o mesmo critério: o critério da liberdade. No mero sentimento, no prazer e na dor, nas paixões que agitam o homem, este é determinado pelo exterior, ele se sente sujeitado e entregue a elas. Mas há uma esfera em que essa passividade cessa imediatamente, e só lá encontramos aquele verdadeiro eu, portador do sentimento religioso. Nesse ponto, Rousseau transcende as limitações da psicologia sensualista. 0 eu não é um dado dos sentidos e jamais pode ser concebido como simples produto dos dados dos sentidos. Ele é atividade originária e a única evidência de tal atividade disponível ao homem. Essa espontaneidade do eu, não sua receptividade, é o sigilo do divino. A quem não é capaz de pensar em si mesmo como em um ser livre, está impedido qualquer acesso a Deus (Cassirer, 1945, pp.46-47).

A redefinição proposta por Cassirer da noção rousseauniana de sentimento consiste - nos parece - em sua racionalização em sentido puro prático, como confirmado notadamente pela segunda parte do argumento: é nossa autoconsciência imediata e evidente de sermos seres espontâneos e livres que nos permite o reconhecimento do divino em nós, sob a forma da lei moral, representação universal, necessária e objetiva de nosso eu como mera forma de atividade. Analogamente, na concepção rousseauniana da religião, a vontade como poder (Vermögen) independente da sensibilidade, portanto autônomo, torna-se condição necessária 
para o reconhecimento da "voz da alma":

Nenhum ser material é ativo por si mesmo, mas eu o sou. Por mais que me contradigam quanto a isso, sinto-o, e esse sentimento que fala a mim é mais forte que a razão que o combate. Tenho um corpo sobre o qual os outros agem e que age sobre eles; essa ação recíproca não é duvidosa, mas minha vontade é independente dos meus sentidos; consinto ou resisto, sucumbo ou sou vencedor, e sinto perfeitamente em mim mesmo quando faço o que quis fazer ou quando apenas cedo à minhas paixões. Tenho sempre o poder de querer, não a força de executar. Quando me entrego às tentações, ajo conforme o impulso dos objetos externos. Quando me censuro por tal fraqueza, só ouço a minha vontade; sou escravo por meus vícios e livre por meus remorsos; o sentimento de minha liberdade só se apaga em mim quando me depravo e enfim impeço a voz da alma de se elevar contra a lei do corpo (E [IV, Profession de foi], OC IV, pp.585-586; p.395).

Nesse sentido, Cassirer não deixa de ressaltar que para Rousseau, afinal, coração, voz interior e instinto divino representam apenas aspectos de um único elemento fundacional tanto da experiência religiosa quanto da moralidade toda: a consciência, como expressão do princípio puro prático de um ser limitado, mas inteligente e livre.

Consciência! Consciência! Instinto divino, imortal e celeste voz; guia seguro de um ser ignorante e limitado, mas inteligente e livre; juiz infalível do bem e do mal, que tornas o homem semelhante a Deus, és tu que fazes a excelência de sua natureza e a moralidade de suas ações; sem ti nada sinto em mim que me eleve acima dos animais, a não ser o triste privilégio de perder-me de erro em erro com o auxílio de um entendimento sem regra e uma razão sem princípio (E [IV, Profession de foi] OC IV, pp.600-601; pp.411-412).

Trata-se daquela mesma consciência que permite compreendermos a necessidade de submeter nossa liberdade particular à lei de liberdade, para que possamos nos afirmar como verdadeiramente livres, tanto na relação interna que instauramos conosco mesmos, como nas relações externas com nossos semelhantes (cf. Cassirer, 1945, p.47).

Esse tipo de conclusão não convence a Derathé, que objeta a Cassirer aquele mesmo vício interpretativo que este questionava a Beaulavon. Segundo Derathé, é preciso conceder a Cassirer o mérito de apontar claramente para a questão crucial, isto é: uma vez aceita a definição rousseauniana de consciência como sentimento, entender como interpretar tal sentimento todo peculiar, que, ao distinguir-se dos dados dos sentidos, de sentimentos e paixões particulares, garante a todos os homens um sentir unívoco e comum. Todavia, ao mesmo tempo, é igualmente necessário reconhecer que o sentimento da consciência, por definição, não é assimilável à razão. De resto, o próprio Rousseau lembra que "Saint Preux faz da consciência moral um sentimento e não um juízo, o que é contra as definições dos filósofos" (NH [VI, carta 7], OC II, p.683; p.587). 
Derathé, então, entende perfeitamente o cerne da operação interpretativa de Cassirer, para o qual "trata-se de reduzir o hiato entre consciência e razão". De outro lado, porém, Derathé não pode não ressaltar que "a sua interpretação [de Cassirer], que acaba identificando-as [consciência e razão] e lembra portanto a de Beaulavon, apresenta o grave inconveniente de inclinar Rousseau para uma teoria que ele [Rousseau] explicitamente combateu, ao formular sua própria concepção da consciência, a saber, o intelectualismo" (Derathé, 1948, p.189). Em outros termos, Cassirer, em nome de um rigoroso espírito de sistema, "ao pretender fazer de sua doutrina [de Rousseau] uma espécie de kantismo ante litteram, acaba desnaturando-a ou mutilando-a" (idem, p.188).

Mas em que consiste o caráter intelectualista que Derathé contesta na interpretação de Cassirer? Não vimos que, ao explicar a consciência como voz divina de nosso coração, Cassirer explicitamente a refere à razão pura prática, à forma da vontade? Derathé, no entanto, atentamente nota como, para Cassirer, em última instância, a consciência em Rousseau, ao ser lida através de Kant, mesmo como expressão pura prática da razão, não pode deixar de compartilhar com esta sempre também sua atividade judicativa. Além desse destaque ser confirmado por palavras explícitas de Cassirer em Das Problem Jean-Jacques Rousseau (cf. Cassirer, 1932, p.76) e indiretamente, como visto, na passagem cassireriana contra o psicologismo sensualista, nos parece aderente e fiel ao pensamento kantiano, em que o binômio principium dijudicationis e principium executionis aparece desde a década de 1770 (cf. Ethik Menzer, p.50). O caráter de causa determinante com relação à vontade e o caráter de (re)conhecimento imediato de nossa natureza (de nossa ratio essendi) como transcendentalmente livre, se encontram ao mesmo tempo distinguíveis e ligados de maneira indissolúvel na espontânea atividade prática da razão que Kant chama de consciência. Derathé, ao objetar a Cassirer uma interpretação de Rousseau exacerbadamente kantista, aponta - justamente, a nosso ver - para uma aplicação indevida de um aparato teórico a outro sensivelmente diferente, ou seja, questiona uma aproximação entre consciência e razão - embora prática - tão forte que acaba na identificação delas e, portanto, em uma desnaturação da proposta de Rousseau. Na verdade, como visto, não apenas uma desnaturação, mas também uma mutilação, pois consequência da interpretação de Cassirer seria a necessária unidade indistinta do viés sentimental e do racionalista.

Não podemos aceitar sem reserva uma conclusão tão radical - afirma Derathé. Bem concordamos que haja em Rousseau uma moral de inspiração racionalista, uma pura moral da lei; mas não se trata senão de um aspecto de seu pensamento. (...) Do lado da moral da virtude (...) Rousseau manteve uma moral da bondade, que pareciathe menos sublime mas muito mais eficaz! Ele não acreditava que o homem fosse tão forte ao ponto de ficar constantemente submetido à lei da virtude: eis porque pareceu-lhe necessário que a natureza viesse de certo modo suprir as falhas de nossa 
vontade (Derathé, 1948, p.187).

Se o caminho para a lei da virtude se dá através da atividade racional do ser humano, a lei natural da bondade se apresenta para nós com o "caráter de legado primitivo ou de conhecimento imediato" (Derathé, 1948, pp.189-190), que guia nossa atividade racional, sem implicar por sua vez qualquer atividade judicativa. Ainda na Profession de foi du vicaire savoyard, Rousseau afirma com todas as letras a distinção entre consciência, como sentir imediato e, portanto, certo, e razão, como faculdade que por si só, em alguma medida, sempre desvia da primeira: “Basta consultar-me sobre o que quero fazer; tudo quanto sinto estar bem está bem, tudo quanto sinto estar mal está mal. O melhor de todos os casuístas é a consciência, e é só quando regateamos com ela que recorremos às sutilezas do raciocínio" (E [IV, Profession de foi], OC IV, p.594; p.404).

É só a partir da distinção entre a consciência como sentimento imediato, de um lado, e a razão, do outro, que, segundo Derathé, é possível entendermos que o princípio que fundamenta o modus philosophandi de Rousseau consiste exatamente na relação entre essas duas distintas fontes da atividade humana, não em sua identificação. Podemos observar novamente como o fim ao qual tende a atividade humana é explicitamente de tipo prático-moral, mas é preciso ressaltar que, ao mesmo tempo, a interação entre sentimento e razão se encontra em ato e em exercício em nós também quando nos interrogarmos sobre tal interação mesma: é a própria interação entre sentimento e razão - a qual, eminentemente, se manifesta na esfera moral - que permite seu reconhecimento como princípio geral de qualquer atividade, inclusive a cognitiva. É nesse sentido que Derathé pode qualificar o método de investigação de Rousseau como racionalismo psicológico ou psicologista. Evidentemente uma leitura kantista à la Cassirer não poderia aceitar essa conclusão, dada a clara separação, em Kant, entre conhecimento propriamente dito, isto é, teórico-especulativo, e "conhecimento prático": ${ }^{8}$ como é notório, este último para Kant, não pode nem deve repercutir no primeiro. ${ }^{9}$ Nem Derathé esconde que, se é "através da intermediação de sua consciência e de sua razão que o homem conquista sua liberdade moral”, é verdade também que é “difícil desembaraçar a

8 Embora a expressão "praktische Erkenntnis" seja utilizada por Kant desde a primeira metade da década de 1750, assim como em 1764 e em 1776-78 (cf., respectivamente, Refl, AA 16: 167 [n. 1948]; GnTM, AA 02: 299.08-18; Refl, AA 18:29 [n. 4923]), ela passa a indicar um conhecimento de tipo prático, em sua acepção de modo de conhecimento ao mesmo tempo legítimo mas diferente do teórico-especulativo, a partir da edição B da primeira Crítica (cf. KrV, B IX.17-X.10 e XXI.01-XXII.01), para confirmar-se na Fundamentação (cf. GMS, AA 04: 389.24-36), consolidando-se definitivamente na segunda Crítica (cf. KpV, AA 05: 20.02-07; 31.14-19; 57.14-23, além das inúmeras perífrases, entre as quais frequente é, por exemplo, "Erkenntnis in praktischer Absicht"). Para as ocorrências no último período crítico, cf. KU, AA 05: 195.01-05 e 475.08-13; RGV, AA 06: 181.29-182.05; RL, AA 06: 225.14-32; Log, AA 09: 86-87; PR Pölitz, AA 28: 11.21-12.10 e 160.02-08.

9 Cf., por exemplo, KpV, AA 05: 50-57, Do direito da razão pura a uma ampliação no uso prático, que por si não lhe é possível no uso especulativo. 
respectiva parte que cabe a cada uma delas nessa libertação progressiva” (Derathé, 1948, p.125).

Todavia, é exatamente a indissolubilidade da relação entre sentimento e razão que nos aponta a dinâmica de nosso aperfeiçoamento, o qual só pode se manifestar na efetiva temporalidade da história, embora seus princípios sejam investigados com pretensão de determinação objetiva. Se as constantes essenciais da natureza humana identificadas por Rousseau são análogas às condições de possibilidade do criticismo kantiano no sentido de que elas se desdobram e se deixam observar em seu dar-se temporal, nos parece que, ao contrário do que ocorre no criticismo kantiano, não haja lugar em Rousseau para uma determinação pura, incondicionada e atemporal, de tais pressupostos originários, exatamente porque o modo de descoberta deles sempre apela à união de formas puras e manifestações empíricas, sendo impossível prescindir destas últimas para pensar as primeiras. Resumindo de modo talvez trivial, para Rousseau, conforme as sugestões da leitura de Derathé, nunca a consciência racional da lei moral seria causa suficiente à determinação de nossa vontade e, assim, ao nosso autoconhecimento prático como seres livres; seja a determinação de nossa vontade, seja o conhecimento de nossa essência moral precisam passar também pela consciência fenomênica, que se distingue - mas não se separa - da consciência pura prática. É como se Derathé estivesse mostrando a Cassirer as consequências de uma leitura anacrônica. Ao pretendermos interpretar Rousseau a partir de Kant sem prejudicarmos o primeiro, no máximo, poderíamos deslocar para a fundamentação objetiva da consciência sentimental aquele que o criticismo kantiano só considerará como o ponto de vista subjetivo e dialético da razão pura prática. Ou seja: ao pretendermos interpretar Rousseau a partir de Kant sem prejudicarmos o primeiro, acabaríamos prejudicando o segundo. Podemos então retomar o que adiantávamos da conclusão de Derathé, identificando na consciência o guia da sã razão. Agora o argumento pode ser mostrado em sua completude, isto é, na duplicidade que o caracteriza:

se Rousseau faz depender o desenvolvimento da consciência das luzes da razão, igualmente submete a razão ao direcionamento da consciência. Quando a razão foge desse direcionamento e não se apoia senão em si mesma, ela desvia do reto caminho da verdade para cair no erro. Não nos esqueçamos de que a consciência nunca nos engana, enquanto pertence frequentemente à razão de nos extraviar (Derathé, 1948, pp.125-126),

como dito, nem tanto e somente em nossos conhecimentos teóricos, como, sobretudo, em nossas deliberações e ações. Portanto, embora certas formulações possam apresentá-las como contraditórias, entre consciência e razão existe sim uma distinção, mas não uma separação nem uma antítese real, pois ambas compartilham, além da necessária complementaridade, a certeza indubitável de qualquer faculdade 
natural.

Se, na reflexão sobre os princípios, encontramos a relação de direcionamento recíproco entre consciência e razão, olhando para esse binômio como se fosse dado de uma vez por todas, evidentemente, como qualquer outra faculdade investigada a partir de - e em - sua manifestação temporal, tanto a consciência como voz do coração, quanto a razão podem ser observadas em seu corromper-se, à medida que abram mão uma da outra. Se aceitarmos a leitura de Derathé, também a contradição entre a veracidade natural da consciência - que podemos adscrever ao primeiro nível de discurso, o da reflexão sobre os princípios - e sua possível corrupção - que podemos adscrever ao segundo nível de discurso, o da realização factual -, perceberemos que resulta apenas como aparente, pois, se é verdade que a consciência necessariamente nunca engana por seu caráter natural, é verdade também que ela necessariamente nunca é estática, mas sempre sujeita a movimento. A consciência, como sentimento natural em movimento, manifestar-se-á como consciência já corrompida e degenerada, quando não guiada pelas luzes da razão, mas pelas paixões sofisticadas próprias da civilização. A mesma dinâmica encontra-se em ato relativamente à razão, quando reivindicar perfeita autossuficiência: nesse caso, ela extraviar-se-á dos ditames naturais.

É nesse sentido que Derathé entende a supracitada invocação à consciência, qual instinto divino e voz imortal e celeste, presente na Profession de foi. Igualmente, assim pode ser lido o apelo à voz da consciência que se encontra ao fim do primeiro Discours: "Oh virtude, ciência sublime das almas simples! Serão necessários tantas labutas e tanto aparato para conhecer-te? Teus princípios não estão gravados em todos os corações? E não basta, para aprender tuas leis, voltar-se a si mesmo e escutar a voz da consciência no silêncio das paixões?" (DCA [II], OC III, p.30; p.40). ${ }^{10}$ Se de um lado é preciso distinguir a consciência da razão, de outro elas só operam em constante relação recíproca: o necessário ato de racionalização pelo qual a voz do sentimento da consciência assume uma forma para nós reconhecível - ato este que pressupõe a distinção entre a esfera da consciência como sentimento e a da razão -, só se dá, pois possibilitado pela relação harmônica, natural e incindível,

10 A mesma observação voltará 27 anos depois, em Les Rêveries du promeneur solitaire: "Sempre disse a mim mesmo: tudo isso são apenas argúcias e sutilezas metafísicas que não têm nenhum peso ao lado dos princípios fundamentais adotados pela minha razão, confirmados por meu coração e que trazem todos o selo do assentimento interior no silêncio das paixões. Em matérias tão superiores ao entendimento humano, uma objeção que não posso resolver derrubará todo um corpo de doutrina tão sólido, tão bem encadeado e formado por tanta medição e cuidado, tão bem apropriado à minha razão, a meu coração, a todo o meu ser e reforçado pelo assentimento interior, que sinto faltar a todos os outros? Não, vãs argumentações nunca destruirão a conformidade que percebo entre minha natureza imortal e a constituição deste mundo e a ordem física que nele vejo reinar. Encontro na ordem moral correspondente, e cujo sistema é o resultado de minhas buscas, o apoio de que preciso para suportar as infelicidades de minha vida" (RPS [ $3^{\mathrm{a}}$ caminhada 1777], OC I, p.1018-1019; p.47). 
entre consciência e razão.

Nem parece-nos paradoxal enxergar nesse aspecto - a necessária dinamicidade real de consciência e razão - um possível terreno de reaproximação das duas interpretações expostas, se a ambas atribuirmos a percepção mais ou menos germinal que tanto a consciência entendida como razão pura prática, quanto a relação entre o sentimento da consciência e a razão, representam princípios de certa forma teleológicos, quando observados à luz da filosofia político-moral seja rousseauniana bem como kantiana. Ressaltamos apenas que a reflexão sobre a consciência como princípio que se desdobra manifestando-se em vista de um fim, a saber, a tentativa de realização política do caráter moral do homem, talvez sirva para reafirmar, mais uma vez, a possibilidade de um Rousseau racionalista e sistemático. Essa chave de leitura revela toda sua sugestiva fecundidade na interpretação de Rousseau por parte de Weil.

Se, de um lado, aos olhos de Weil, os resultados alcançados por Derathé são incontestáveis e necessários para qualquer ulterior investigação voltada à compreensão da filosofia rousseauniana, ao mesmo tempo, Weil declara imediatamente sua pretensão de amplificar tal interpretação, indo “mesmo mais longe dele [de Derathé]”. Segundo Weil, Derathé “acerta” em sustentar "que Rousseau foi racionalista”, pois "não apenas o afirma, mas o prova”, ao mostrar que "a razão deve esclarecer o coração para preservá-lo do erro e da depravação"; e que "sem ela não há nem virtude, nem bondade, nem humanidade" (Weil, 1952, p.116). Evidentemente, desde o início de sua avaliação, ao enfatizar, não aquele influxo recíproco entre o sentimento da consciência e a razão que Derathé ressalta em Rousseau, mas a ação unilateral da razão sobre o coração, Weil está concordando apenas parcialmente com Derathé. Para Weil, de resto, trata-se de “muito mais", pois

Rousseau descobre o conceito moderno de razão, de uma razão que, como unidade de teoria e ação, de pensamento e moral, de consciência individual e lei universal, se opõe ao entendimento formal, à "razão" dos raciocinadores e dos "philosophes" execrados por Rousseau; ele descobre, em suma, o que produzirá, com Kant, a única novidade que a história da filosofia tenha conhecido (Weil, 1952, pp.116-117).

À primeira vista, parece que Weil, ao remeter-se explicitamente à esfera moral e política, reproponha a tese de Cassirer, despercebendo a distância profunda que - como tentamos reconstruir - o próprio Derathé coloca entre sua interpretação e a cassireriana: aceita-se que a razão em Rousseau desempenhe papel diferente daquele do entendimento teórico, mas não ao custo de reduzir a relação entre o sentimento da consciência e a razão, presente em Rousseau, à razão prática de Kant. Nem, quanto a isso, Derathé deixa margem a dúvidas:

Para Rousseau, a razão permanece guia seguro em seu uso prático, ao passo que corre o risco de extraviar-se em sua função especulativa quando se aventurar além de seus 
limites naturais. Encontramos, portanto, em germe, em Rousseau, a distinção que será mais tarde elaborada por Kant entre a razão especulativa e a razão prática. Todavia, Rousseau não concebe a natureza da razão como Kant. Nada é mais alheio ao seu pensamento [de Rousseau] que um sistema rígido de categorias (Derathé, 1948, p.177).

Derathé aponta para o que Kant reiteradamente afirma acerca da razão em seu uso prático, isto é, que, também em sua relação com a vontade, a razão continua operando segundo sua forma, notadamente segundo a da determinação causal implícita no conceito de lei em geral, ${ }^{11}$ embora se trate aqui daquela que Kant chama de causalidade por liberdade. Apesar de não se deter na concepção de razão prática em Kant - de resto, não é esse o intuito de sua análise -, Derathé, de um lado, admite o estorvo na tentativa de "definir a natureza da razão em Rousseau, pois não há, em sua obra, propriamente falando, uma teoria do conhecimento"; de outro, afirma que "em contrapartida, encontramos duas definições da razão, uma emprestada de Condillac, a outra de origem malebranchista” (Derathé, 1948, p.177). Nesse sentido, a primeira definição consentiria a Rousseau se referir à razão não como a uma faculdade propriamente dita, pois consistiria no uso judicioso, harmônico, de todas as faculdades entre si, conforme Rousseau afirma em Émile, quando identifica na razão, "por assim dizer, um composto de todas as outras faculdades humanas" (E [II], OC IV, p.317; p.89). Já a segunda definição remete à concepção da razão conforme proposta por Rousseau na segunda das Lettres morales, na qual se lê que

A arte de raciocinar não é absolutamente o mesmo que a razão: frequentemente é o seu abuso. A razão é a faculdade de ordenar todas as faculdades de nossa alma de forma adequada à natureza das coisas e a suas relações conosco. 0 raciocínio é arte de comparar as verdades conhecidas para compor a partir delas outras verdades as quais ignorávamos e que essa arte nos faz descobrir" (LM [carta 2], OC IV, p.1090; pp.33-34). ${ }^{12}$

Então, Weil assumiria apenas as premissas de Derathé, para chegar, na verdade, à conclusão de Cassirer. A proximidade entre Cassirer e Weil encontraria, pois, ulterior confirmação pela aplicação por parte do segundo do mesmo método de reconstrução historiográfica inaugurado pelo primeiro. Cassirer sustentara que

$11 \mathrm{Cf} .$, por exemplo, KpV, AA 05: 28.34-29.23.

12 Dada a comparação entre Weil e Derathé aqui proposta, nos parece interessante notar, se bem que apenas de passagem, que as duas definições que Derathé recorda a partir do Émile e das Lettres morales, e reconduz, respectivamente, ao "plano psicológico" e ao "domínio metafísico", lembram, de certo modo, a razão concebida como faculdade do juízo, conforme proposto por Kant, por exemplo, na introdução de $K U$. A razão como faculdade que julga de modo reflexionante em perspectiva teleológica, isto é, de um modo alheio a seu uso especulativo e seu uso prático, encontra legitimidade transcendental, portanto objetiva, como resposta à necessidade meramente subjetiva de encontrar sentido no mundo, mesmo que a tal sentido não corresponda um domínio de conhecimento. Assim lida, à razão como faculdade do juízo reflexionante teleológico parecem adequar-se tanto a função de harmonização das faculdades entre si, quanto a de organização delas em vista de o homem poder se orientar no mundo e compreender a si mesmo. 
os pensamentos fundamentais de Rousseau, se bem que nascidos imediatamente de seu ser e sua particularidade, não permanecem todavia fechados e ligados a essa particularidade individual, mas, em sua maturidade e completude, colocam na nossa frente uma problemática objetiva que não possui valor só para ele mesmo [Rousseau] e sua época, mas contém em si, com toda nitidez e definição, uma necessidade interior rigorosamente objetiva. Porém, essa necessidade não nos se mostra logo em uma abstrata universalidade e distinção sistemática. Ela vai se libertando aos poucos do substrato individual originário do ser de Rousseau e desse fundo originário deve ser, de certo modo, arrancada e conquistada passo a passo (Cassirer, 1932, p.11).

É nessa perspectiva metodológica que, para Cassirer, no que diz respeito à natureza político-moral da razão, quem “compreendeu plenamente Rousseau foi o único pensador ético absoluto que o século XVIII produziu, o defensor do 'primado da razão prática'” (Cassirer, 1932, pp.49-50): Kant foi o único que soube definir os pensamentos fundamentais de Rousseau, os que o próprio Rousseau não declarou espontaneamente. Acompanhando essa mesma linha interpretativa, Weil se pergunta:

não precisava um Kant para ver o que Rousseau expressara sem ter sabido pensálo no sentido forte do termo, sem ter conseguido desenvolver os pressupostos e as consequências, os desdobramentos práticos e as conclusões teóricas? E Rousseau não parava no meio do caminho porque o homem, o autor não era racionalista em sua atitude de homem e de autor, porque essas consequências e esses pressupostos não o interessavam de modo algum, porque o que, em Kant, se tornava teoria e filosofia, para ele [Rousseau] não era senão mais um meio para formular e exteriorizar o conflito de sua pessoa, aquela dilaceração de seu ser todo, que fez dele um louco e um gênio? (Weil, 1952, p.117) ${ }^{13}$.

Assim Weil pode confirmar, de acordo com Derathé - e, "antes dele Beaulavon e Cassirer" -, que "o racionalismo de Rousseau não é o do racionalista” (Weil, 1952, pp.117 e 123) intelectualista cartesiano, bem como, de acordo com Cassirer, que é necessário Kant para compreender Rousseau. Não espanta, então, que Weil, como Cassirer, reconheça certa ambiguidade em Rousseau, cuja assistematicidade não é atribuída ao pensamento ou, ao menos, ao caráter unitário que do pensamento rousseauniano deve ser descoberto e realizado; ao contrário, a ambiguidade de Rousseau encontra seu exato lugar e consiste na discrepância que se interpõe entre o pensador e o homem, exigindo-se um Kant para que a Rousseau seja dada voz sem que Jean-Jacques interfira.

Até Kant - repete Weil, ecoando Cassirer - ninguém compreendeu o pensamento de Rousseau e Rousseau foi o primeiro a não compreendê-lo: precisava de Kant, precisava de um Kant para que Rousseau se tornasse, ex parte post, um filósofo. Mas o fato é que ele [Rousseau] se torna tal a partir do dia em que, no espírito de Kant,

$13 \mathrm{Na}$ verdade, nesse mesmo sentido, já o próprio Kant apontara para a necessidade de sua intervenção: "Podemos acordar entre si e com a razão, as afirmações do célebre J.-J. Rousseau, que aparentemente se contradizem e foram tão amiúde mal compreendidas" (MAM, 08: 116.0508). 
provocou a única revolução de toda a história da filosofia após Platão, e foi, nesse filho espiritual, o pai da nova concepção de razão (Weil, 1952, pp.123-124).

Parece-nos, no entanto, que Weil não se limite a retomar a leitura de Cassirer, mas acabe indo além dela, assim como explicitamente pretende ir além de Derathé. Concluindo o raciocínio anterior, Weil apresenta finalmente a que achamos uma indicação tanto rápida quanto preciosa do núcleo original de sua interpretação: "Se precisava de um gênio para tirar de Rousseau o que Kant tirou, mesmo um gênio naquele momento não podia encontrá-lo em outro lugar" (Weil, 1952, p.124). Trata-se de um movimento de mão dupla: se é verdade que é preciso Kant para transformar o pensamento rousseauniano em filosofia, é bem verdade também que é preciso Rousseau para que a filosofia kantiana exista; se Kant torna-se intérprete necessário, para que os pensamentos fundamentais de Rousseau adquiram forma, complementarmente os pensamentos fundamentais de Rousseau constituem-se como dado igualmente necessário, para que o ato interpretativo de Kant realize a moldagem. Poderíamos dizer que Weil, em um primeiro momento, leia a própria relação Rousseau-Kant como análoga àquela que fundamenta a KrV: há conhecimento desde que se pressuponha como necessária a relação entre sujeito e objeto, sem que se possa clamar por uma primazia de um ou de outro, pois o primeiro só é capaz de dar forma ao segundo na medida em que o segundo é apto a ser moldado só pelo primeiro, permanecendo desconhecido, pois indeterminável, tudo aquilo que for considerado em si, fora da relação. Nesse sentido, é indicador o incipit do ensaio de Weil, que de pronto orienta as páginas seguintes: "Há um só Rousseau? Podemos, ao menos, construir uma unidade a partir de Rousseau?" (Weil, 1952, p.115). Parafraseando: Há um Rousseau em si? Se não pudermos responder a essa primeira pergunta, é possível ao menos conhecermos Rousseau a partir de como ele se dá nem tanto a seus intérpretes, mas àqueles cujo pensamento depende das ideias do próprio Rousseau?

Weil percorre convictamente esse segundo caminho e, a partir da sugestão inicial, leva às últimas consequências sua opção hermenêutica. É nessa perspectiva que Kant, segundo Weil, faz deflagrar a única verdadeira revolução da história da filosofia, a que deve a Rousseau a paternidade da nova concepção da razão em todos seus aspectos e usos:

a razão, ao mesmo tempo teórica e prática, é, em sua natureza e destinação mais profunda, liberdade e consciência imediata da lei de liberdade; ela não é teórica senão para poder fugir, por uma tomada de consciência, ao mecanismo e determinismo metafísico dos "philosophes", ela é e sabe-se moral, e para ela não há outro valor senão o respeito por si mesma como respeito pela universalidade da lei racional, da razão legisladora no tribunal do indivíduo; ela é ação, não se deixa acorrentar por nenhuma ciência do entendimento; ela é vida e escarnece as pretensões de um saber mecânico, de um saber de morte; e, já que ela é vida, qualquer um se quiser participar e ser livre na razão, participa dela, o ignorante bem como o sábio. 0 indivíduo não determinado: nas determinações sempre relativas e fenomênicas do mundo, ele se 
determina de forma absoluta, isto é, de uma maneira que é imediatamente evidente e certa, e que, por isso mesmo, não pode parecer senão loucura aos olhos da ciência desse mundo (Weil, 1952, p.124).

Weil antecipa aqui a mesma linha argumentativa que, com mais vagar, uma dezena de anos depois proporá em Problèmes kantiens como subjacente à sua leitura da inteira filosofia crítica kantiana. ${ }^{14} \mathrm{~A} \mathrm{KrV}$, ao sistematizar o método de investigação do idealismo transcendental, dá, sim, o primeiro passo na direção da compreensão racional do mundo através da possibilidade real da experiência, mas, desde logo, revela a insuficiência do conhecimento científico no que diz respeito à exigência de a própria razão afirmar-se como liberdade. Aliás, é a partir dessa insatisfação para com seu "peculiar destino" 15 que a razão se reconhece, desde a $\mathrm{KrV}$, como legitimamente livre, embora em sentido apenas regulativo. Será a $K p V$ que mostrará ser a razão realmente autônoma enquanto consciência de si como mera forma da lei, portanto, legisladora absolutamente livre e universal. Mas só a KU atenderá, fundamentando-a transcendentalmente, a necessidade subjetiva de o mundo e a vida fazerem sentido para nós, sendo que nós mesmos somos, enquanto seres livres, origem do sentido do mundo. Então a política será o banco de prova da tensão da razão como liberdade em busca de sentido em um mundo que, na esfera da liberdade que desconsidera o sentido insatisfatório do determinismo mecânico, parece não oferecer sentido algum. Mais especificamente, é a tensão que se revela no jogo entre moral e política que torna-se o foco da relação biunívoca entre Rousseau e Kant, conforme a vimos estabelecida por Weil.

Se o homem constitui o fim último da natureza entendida como sistema teleológico, conforme o juízo reflexionante autoriza, isto é, se o mundo, para fazer sentido para nós, deve poder ser concebido por nós como voltado a um fim superior a qualquer fim particular, sendo esse fim o próprio homem como ser racional e livre, então

a condição formal, sob a qual somente a natureza pode alcançar esta sua intenção última, é aquela constituição na relação dos homens entre si, onde ao prejuízo recíproco da liberdade em conflito se opõe um poder conforme leis num todo que se chama sociedade civil, pois somente nele pode ter lugar o maior desenvolvimento das disposições naturais (KU, AA 05: 432.26-32).

É a ideia de contrato social que, afinal, permite a Kant devolver à razão aquele

14 Além de Weil repropor, tanto na impostação geral da coletânea, quanto na específica do terceiro ensaio sobre Histoire et politique, uma linha argumentativa muito próxima da citada, lembremos também que, nesse mesmo ensaio, Weil voltará à relação entre Rousseau e Kant (cf. Weil, 1963, p.117 nota).

15 "A razão humana tem o peculiar destino, em um dos gêneros de seus conhecimentos, de ser atormentada por perguntas que não pode recusar, posto que the são dadas pela natureza da própria razão, mas que também não pode responder, posto ultrapassarem todas as faculdades da razão humana" (KrV, A VII.01-05). 
papel essencial que o próprio Rousseau, segundo Weil, não conseguira expressar plenamente: a razão, que dá forma à livre atividade humana de procura pelo sentido, manifesta sua função eminente ao fundamentar as relações e as vidas dos homens nas comunidades em que eles se organizam a fim de realizarem sua verdadeira liberdade e, por ela, suas disposições. ${ }^{16}$ Talvez Rousseau não apenas tenha pensado a ideia de contrato nesses termos, mas até chegado a expressá-la. No terceiro capítulo, Du pacte fondamental, da primeira versão do Contrat social, Rousseau se refere ao contrato como a um princípio de razão necessário para que se deem as condições, com a instituição do Estado, de nossa plena realização como seres humanos:

Essa passagem do estado da natureza para o estado social produz no homem uma mudança notável, ao substituir no seu comportamento o instinto pela Justiça, ao dar às suas ações um significado moral que antes não tinham. Só então, quando a voz do dever toma o lugar do impulso físico, e o direito substitui o apetite, o homem, que até então só levava em conta a si mesmo, descobre que está obrigado a agir segundo outros princípios, e a consultar a razão antes de obedecer às suas inclinações pessoais. Mas, embora nesse estado não tenha algumas das vantagens proporcionadas pela natureza, ele se beneficia de outras mais importantes, exercita e desenvolve suas faculdades, amplia suas ideias, enobrece seus sentimentos e eleva toda a sua alma a um ponto tal que, se o abuso da sua nova condição não o degrada a uma situação inferior à de antes, deveria abençoar o momento feliz que dela o afastou para sempre, transformando-o de um animal estúpido e limitado em um ser inteligente - em um homem (MG [I.iii], OC III, p.292; p.125).

De todo modo, apesar de precisar - ou não - de um Kant para pensarmos os verdadeiros pensamentos de Rousseau, podemos convir com Weil que, só se considerarmos a centralidade da sociedade civil para a vida de um ser racional finito, cuja liberdade o leva ininterruptamente à procura de sentido, talvez compreendamos também o intuito geral e a unidade sistemática do pensamento de Rousseau, por trás de suas discrepâncias.

\section{Referências}

Attridge, A. (1974). The reception of La Nouvelle Héloïse. Studies on Voltaire and the Eighteenth Century, 120, pp.227-267.

Cassirer, E. (1932). Das Problem Jean-Jacques Rousseau. Archiv für Geschichte der Philosophie, 41 (1 e 3), pp. 177-213 e 479-513 (versão ampliada do texto da

16 Lembremos que a passagem já citada (cf. infra, nota 15) justamente continua assim: "Em seus escritos sobre a Influência das ciências e sobre a Desigualdade entre os homens, ele [Rousseau] mostra, com justeza, o inevitável antagonismo entre a cultura e a natureza do gênero humano como espécie física, no qual todo o indivíduo deve realizar plenamente a sua determinação; mas no Emílio, Contrato social e outros textos, ele busca resolver um problema ainda mais difícil: saber como a cultura deve progredir para desenvolver as disposições da humanidade, como espécie moral, conforme a sua destinação, de sorte que esta última não se oponha à primeira, à espécie natural” (MAM, AA 08: 116.08-17). Para a centralidade da noção de "bürgerliche Gesellschaft" em relação ao tema do desenvolvimento do homem como ser racional e moral, cf., ainda na década de 80, laG, 08: 122.05-37, e, já na década de 90, TP, AA 08: 289.08-290.25; ZeF, AA 08: 371.01-24; RL AA 06: 340.23-341.22; SF, AA 07: 90.22-91.18. 
conferência de 27 de fevereiro de 1932, publicado como: L'unité dans l'œuvre de J.-J. Rousseau. Bulletin de la Société Française de Philosophie, 32 (2), pp. 46-66). As indicações das páginas seguem: Kreis G. (Org.), Über Rousseau (pp. 7-90). Berlin: Suhrkamp Verlag, 2012.

(1939). Die Philosophie im XVII. und XVIII. Jahrhundert. Paris: Hermann et Cie. Editeurs.

(1945). Kant und Rousseau [1939], aparecido como: Kant and Rousseau. In : Rousseau Kant Goethe. Tradução de James Gutman, Paul Oskar Kristeller, John Herman Randall Jr.. Princeton, NJ: Princeton University Press $\left(2^{\mathrm{a}}\right.$ ed. ampl. 1963).

Comte, A. (1853). Système de politique positive. Tome III. Paris: Carilian-Goeury et Dalmont. Disponível em: https://books. google.com.br/books?id=gA_dCYqRZSEC\&printsec=frontcover\&dq $=$ Syst \%C $3 \%$ A 8 me +de + politique + positive\&hl=it\&sa =X\&redir esc $=\mathrm{y} \# \mathrm{v}=$ onepage\&q\& $\mathrm{f}=\mathrm{false}$

Derathé, R. (1948). Le rationalisme de Jean-Jacques Rousseau. Paris: PUF.

Kant, I. Kants Gesammelte Schriften (AA). Preußische Akademie der Wissenschaften (vol. 01-22); Deutsche Akademie der Wissenschaften (vol. 23); Akademie der Wissenschaften zu Göttingen (vol. 24-29), 1902ss.. Indicam-se apenas os textos kantianos cujas passagens foram citadas diretamente:

(1781) Kritik der reinen Vernunft (KrV, A). Crítica da razão pura. Trad. de Fernando Costa Mattos. Petrópolis, RJ: Editora Vozes, 2012 (20154).

- (1786) Muthmaßlicher Anfang der Menschengeschichte (MAM, AA 08: 109-123). Começo conjectural da história humana. Trad. de Edmilson Menezes. Editora Unesp, 2009.

. (1790) Kritik der Urteilskraft (KU, AA 05: 167-485). Crítica da faculdade do Juízo. Tradução de Valério Rohden e António Marques. Rio de Janeiro, RJ: Forense Universitária, $2010\left(2012^{3}\right)$.

Labrosse, C. (1985). Lire au XVIIlè siècle: La Nouvelle Héloïse el ses lecteurs. Lyon: Presses Universitaires Lyon.

Rousseau, J.-J. (1959-1995). CEuvres complètes (OC). Edição sob a direção de Bernard Gagnebin e Marcel Raymond, 5 volumes. Paris: Gallimard.

- (1750). Discours sur les sciences et les arts (DCA, OC III). Discurso sobre as ciências e as artes. In: Discurso sobre a origem e os fundamentos da desigualdade entre os homens precedido de Discurso sobre as ciências e as artes (pp. 1-40). Tradução de Maria Ermantina Galvão. São Paulo, SP: Martins Fontes, $1993\left(2005^{3}\right)$.

(1755). Discours sur l'économie politique (EP, OC III). Tratado sobre a economia política. In: Gelson Fonseca Jr. (Org.), Rousseau e as relações internacionais (pp. 1-43). Trad. de Sérgio Bath. Brasília, DF/São Paulo, SP: Editora UnB/FUNAG-IPRI/Imprensa Oficial do Estado de São Paulo, 2003.

(1758). Lettres morales (LM, OC IV). Cartas morais. In Carta a Christophe de Beaumont e outros escritos sobre a religião e a moral (pp. 139- 
174). Trad. e org. de José Oscar de Almeida Marques. São Paulo, SP: Estação Liberdade, 2005.

- (1761). Du Contrat social (première version, manuscrit de Genève) (MG, OC III). Sobre o contrato social (primeira versão). In: Gelson Fonseca Jr. (Org.), Rousseau e as relações internacionais (pp. 1-43). Trad. de Sérgio Bath. Brasília, DF/São Paulo, SP: Editora UnB/FUNAG-IPRI/Imprensa Oficial do Estado de São Paulo, 2003.

- (1761). La Nouvelle Héloïse (NH, OC II). Júlia ou A Nova Heloísa: carta de dois amantes habitantes de uma cidadezinha ao pé dos Alpes. Trad. de Fúlvia Maria Luiza Moretto. São Paulo, SP/Campinas, SP: Hucitec/Ed. Unicamp, 1994.

(1762). Émile ou De l>éducation (E, OC IV). Emílio ou Da Educação. Trad. de Roberto Leal Ferreira. São Paulo, SP: Martins Fontes, 1995 (2004³).

(1762). Lettre à Christophe de Beaumont (LCB, OC IV). Carta a Christophe de Beaumont. In:Carta a Christophe de Beaumont e outros escritos sobre a religião e a moral (pp. 37-117). Trad. e org. de José Oscar de Almeida Marques. São Paulo, SP: Estação Liberdade, 2005.

. (1782). Les Rêveries du Promeneur solitaire (RPS, OC I). Os devaneios do caminhante solitário. Trad. de Fúlvia Maria Luiza Moretto. Brasília, DF/São Paulo, SP: Editora UnB/Hucitec, 1994.

Taylor, S.S.B. (1963). Rousseau's contemporary reputation in France. Studies on Voltaire and the Eighteenth Century, 27, pp. 1545-1574.

Weil, E. (1952). Jean-Jacques Rousseau et sa politique. Critique, 56, pp. 4-28. As indicações das páginas seguem: Weil E. (Org.). Essais et conférences. Tome 2 Politique (pp. 115-148). Paris: Librairie philosophique J. Vrin, 1991.

(1963). Problèmes kantiens. Paris: Librairie philosophique J. Vrin. $2^{\mathrm{a}}$ ed. ampl. $1970\left(1998^{4}\right)$.

Recebido em: 29.08.2016

Aceito em: 24.11.2016 